\title{
Use of space and dispersal ability of a flagship saproxylic insect: a telemetric study of the stag beetle (Lucanus cervus) in a relict lowland forest
}

\author{
MASSIMILIANO TINI, ${ }^{1}$ MARCO BARDIANI, ${ }^{2,3}$ STEFANO CHIARI, ${ }^{1,3}$ \\ ALESSANDRO CAMPANARO ${ }^{2,3}$ EMANUELA MAURIZI, ${ }^{1,3}$ ILARIA \\ TONI, ${ }^{2}$ FRANCO MASON, ${ }^{2}$ PAOLO A. AUDISIO ${ }^{4}$ and GIUSEPPE M. \\ CARPANETO ${ }^{1} \quad{ }^{1}$ Dipartimento di Scienze, Università Roma Tre, Roma, Italy, ${ }^{2}$ Centro Nazionale per lo Studio \\ e la Conservazione della Biodiversità Forestale 'Bosco Fontana' Carabinieri, Verona, Italy, ${ }^{3} \mathrm{CREA}-\mathrm{ABP}$ Consiglio per \\ la ricerca in agricoltura e l'analisi dell'economia agraria - Centro di ricerca per l'agrobiologia e la pedologia, Firenze, Italy \\ and ${ }^{4}$ Dipartimento di Biologia e Biotecnologie 'C. Darwin', Sapienza Università di Roma, Roma, Italy
}

\begin{abstract}
The stag beetle, Lucanus cervus (Linnaeus, 1758) (Coleoptera: Lucanidae), is a flagship species for the conservation of European old-growth forests. Despite its popularity and many studies conducted, the lack of knowledge of its habits and ecological requirements leads to difficulties in locating the species in the field and to provide information for suitable planning conservation actions suitable for the species.

2. In order to gather information on dispersal ability and space use, a radiotelemetry study was conducted in a relict floodplain forest surrounded by intensively cultivated land. During 2014 and 2015, from May to July, 55 beetles (34 males, 21 females) were radio-tagged, and 9 of these ( 7 males, 2 females) were telemetered immediately after the emergence from their development sites, by means of emergence traps.

3. The use of radio-telemetry allowed to detect the oviposition sites and to study the first part of the adult life, when they resulted to be more active. Males were more prone to disperse than females but the home range size did not differ between the sexes. Dividing the season in three intervals, the most active individuals were recorded during the first and the second ones (first and second half of June).
\end{abstract}

Key words. Coleoptera Lucanidae, dead wood consumers, habitat directive, home range, kernel density estimation, minimum convex polygon, old-growth forests.

\section{Introduction}

The stag beetle, Lucanus cervus (Linnaeus, 1785) (Coleoptera: Lucanidae), is a species listed in the Annex II of the European Directive 92/43/EEC, which states the necessity of monitoring the conservation status of protected

Correspondence: Massimiliano Tini, Dipartimento di Scienze, Università Roma Tre, Viale G. Marconi 446, 00146 Roma, Italy. E-mails: massimiliano.tini@uniroma3.it; massimilianotini82@gmail.com populations and habitats, with special regard to saproxylic insect communities in forest ecosystems (Nieto \& Alexander, 2010; Carpaneto et al., 2015; Mason et al., 2015). Difficulties in monitoring the target species, mainly linked to trap efficiency, were highlighted in previous studies (Harvey et al., 2011b; Chiari et al., 2014; Bardiani et al., 2017). Many aspects on ecology and behaviour of the stag beetle, e.g. selection of sites for oviposition, dispersal patterns, home range size, reproductive behaviour and population biology should be carefully investigated in different environmental conditions, to prevent the local insurgence 
of threats or to mitigate the impact of human activities. In fact, circumstantial evidence indicated some differences in the ecology of this species throughout its distribution range, in relation to climatic conditions, habitat, and landscape (Rink \& Sinsch, 2007, 2011; Harvey et al., 2011a; Campanaro et al., 2016). An understanding of these differences, especially dealing with space use, dispersal ability, and phenology, may be crucial to provide management plans and conservation actions (Turchin, 1998; Manly et al., 2007; Schick et al., 2008). The space use of the stag beetle has never been deeply investigated (e.g. using radio-telemetry) in high-quality habitat conditions as natural old-growth forests. The only telemetric studies of L. cervus were conducted in Switzerland (SprecherUebersax \& Durrer, 2001; Sprecher, 2003) and Germany (Rink \& Sinsch, 2007, 2011), all in suburban settlements, but only the latters were carried out during the entire activity season of the adults. In the aforementioned studies, sexual differences in dispersal behaviour were detected: males use to cover longer distances than females. In fact, males are thought to be responsible of gene flux, while the colonisation of new oviposition sites is related to females. The oviposition site selection may strongly influence the spatial distribution of a species (Hassel, 1987; Pearman \& Wilbur, 1990; Morris, 2003; Rudolf \& Rödel, 2005) in particular for saproxylic beetles, that is, beetles dependent on dead or decaying wood during at least one phase of their life cycle (Speight, 1989).

For saproxylic beetles, identification and protection of suitable micro-habitats for oviposition and larval development are a crucial aspect for their conservation. For the stag beetle males, competition is based on their seasonal dispersal to search females, followed by intraspecific fights between them (Clark, 1977; Sprecher, 2003; Fremlin, 2009). Such dispersal in terms of space and time is probably related to habitat conditions and annual meteorological trends that affect population activity. Considering that the number of active adults varies during the flight season (Chiari et al., 2014; Campanaro et al., 2016; Bardiani et al., 2017), also the intraspecific competition is supposed to vary during the same time span. According to Rink and Sinsch (2007), the first flights of an adult stag beetle are probably longer than the other ones, and their energy and activities are supposed to decrease during the adult life span. Indeed, stag beetles feed rarely during their adult stage; they survive well on their fat reserves during the short flight season (Harvey \& Gange, 2003).

The aim of this study is to give a contribution to some ecological and ethological aspects of the stag beetle in a relict lowland deciduous forest of northern Italy, and to provide information for planning conservation actions suitable for this species. In particular, the following key questions were addressed: (i) Is radio-telemetry suitable for detecting the oviposition sites of stag beetles? (ii) Are there any differences in the use of space between sexes? (iii) Does the dispersal activity mostly occur at the beginning of individual life span? (iv) Does the use of space vary during the flight season?

\section{Materials and methods}

Study area

The study area is 'Bosco della Fontana', a State Nature Reserve (SCI IT20B0011) located in northern Italy (Marmirolo, province of Mantua, Region Lombardy) $\left(45^{\circ} 12^{\prime} \mathrm{N}\right.$ $10^{\circ} 44^{\prime} \mathrm{E}$, altitude: $24-26 \mathrm{~m}$ a.s.1.). This area is one of the last remains (233 ha) of the lowland broadleaf forests in the Po valley, an intensively cultivated area. The forest is a Biogenetic Nature Reserve since 1977 included in the Nature 2000 network as a Special Protected Areas (SPAs IT20B0011) since 1998 and a Site of Community Importance (SCI IT20B0011) since 2004. The Reserve is also part of the Italian Long-Term Ecological Research Network (LTER-Italy) since 2007. Around $85 \%$ of the Reserve is covered by broadleaf forest; the remaining part consists of a grassland and a small wetland. The deciduous forest of the study area is dominated by Quercus cerris L., Quercus robur L., Carpinus betulus L., and Fraxinus ornus L., with Alnus glutinosa (L.) and Fraxinus oxycarpa Vahl along the main watercourses (Mason, 2004). In the Reserve, all silvicultural practices officially terminated in 1994 (Mason, 2004), and forest management was aimed to the increase of deadwood amount for restoring the naturalness of the ecosystem. Such actions were realised by favouring the ageing of alien trees (Quercus rubra L., Juglans nigra L., Platanus spp.) and converting them to coarse woody debris (Cavalli \& Mason, 2003). This management led the area to become an optimal site for many saproxylic organisms, as shown by the abundant populations of large saproxylic species, i.e. Lucanus cervus, Morimus asper (Sulzer, 1776) and Cerambyx cerdo Linnaeus, 1758 (Chiari et al., 2013a; Mason et al., 2015; Campanaro et al., 2016).

\section{Data collection}

From 29th May to 10th July 2014 and from 27th May to 08th July 2015, adults of L. cervus were collected by hand or by an entomological hand net (diameter of frame $50 \mathrm{~cm}$, telescopic handle $199 \mathrm{~cm}$ ). Each captured adult was weighted, marked ventrally with a permanent marker, and with a numbered sticker on the right elytron, and then equipped with an active (battery-powered) radio transmitter (LB-2X/0.31 g; Holohil Systems Ltd., Carp, $\mathrm{ON}$, Canada). As previously done for O. eremita (Chiari et al., 2013b), transmitters were attached to the pronotum using a cyanoacrylate glue (LOCTITE, Super Attack flex Gel; Henkel, Düsseldorf, Germany). The transmitter battery had a nominal lifetime of 21 days but its real duration varied from 13 to 22 days. The antenna of the transmitter was reduced to $5 \mathrm{~cm}$ and adjusted above the elytron suture to limit disturbance to beetle behaviour (Rink \& Sinsch, 2007). According to Boiteau and Colpitts (2001), electronic tags should weigh no more than $33 \%$ of the beetle's weight to avoid impact on the flight; in our 
study, the transmitter weight was $<32 \%$ of the initial body mass. To detect the transmitter signal, a handheld antenna (Yagi three elements; Wildlife Materials Inc., Murphysboro, IL, USA) connected to a radio receiver (NEW TRX-1000S W; Wildlife Materials Inc.) was used.

The radio-tagged beetles were released in the same place where they had been captured and when weather conditions were favourable (no rainfall, mild temperature). The 'homing technique' (White \& Garrott, 1990) was used to detect the location of each beetle. The homing procedure always started at the last known location of the individual and lasted between few minutes to some hours. To avoid direct interference with the tagged beetles, individuals were approached no closer than $0.5 \mathrm{~m}$. When a beetle was found in a new location, a 'relocation' was recorded. Coordinates of each location/relocation were identified using a Garmin GPS (Garmin Ltd., Olathe, KS, USA) (MAP 60 CSX). In some cases, visual detection was possible, but not when individuals were underground, into dead wood or in the canopy. When males stayed underground or within inaccessible dead wood micro-habitats, we waited at least 2 days before checking if the transmitter was detached from the beetle or if it was dead. On the contrary, if a female remained at the same place for 3 days, we waited at least 5 days before checking. If the radio-signal of a female was heard to come from deep underground close to dead wood for at least 3 days, we assumed it to be a potential oviposition site. In the latter case, we did not check, to avoid any interference with possible ovipositing behaviour and to not compromise the fragile equilibrium of these micro-habitats.

When a radio-signal was not found, it was searched by walking from the last location point to a distance of $1 \mathrm{~km}$ in all directions, within the Reserve.

To obtain information on beetle activities during the whole $24 \mathrm{~h}$, slots of $4 \mathrm{~h}$ with six shifts every 6 days were performed. During each slot, for each beetle, one homing per hour was made usually.

In order to capture adults as soon as possible after their emergence from ground [i.e. new emergence beetles (NEB)], we set emergence traps on dead wood spots assumed to be suitable for larval development during the last 3 or 4 years. In the first 15 days of May 2015, on the base of data recorded on females of the previous year, nine emergence traps were set. These traps consisted of wrapping large pieces of decaying wood (standing dead trees, fallen trunks, uprooted trees, logs, snags, and stumps) with anti-aphid plastic nets fixed with nails to the ground or to the wood. Traps were checked at least twice a week until 15 th July.

\section{Data analyses}

The distance between two consecutive georeferenced points (relocation length) was calculated with the free and open source software QGIS ver. 2.6.0 - Brighton, Free Software Foundation, Inc., Boston, MA, USA (QGIS
Development Team, 2014). As previously done in Chiari et al. (2013b), the movements exceeding $5 \mathrm{~m}$ were considered dispersing events. As in Rink and Sinsch (2007), the movements exceeding $20 \mathrm{~m}$ were assumed to be flying events, while shorter movements $(<20 \mathrm{~m})$ may have taken place either by flight or walking. Thus, individuals which performed at least one movement exceeding $5 \mathrm{~m}$ were classified as dispersing individuals, while those which performed at least one movement exceeding $20 \mathrm{~m}$ were flying individuals. The number of dispersing and flying individuals compared to the total number of individuals was calculated for each sex, and difference among sexes was tested. The analysis of dispersing individuals was developed to investigate on movements shorter than $20 \mathrm{~m}$, which could be considered important dispersal events in particular for females, which are thought to cover shorter distances than males, especially in areas with huge amount of dead wood. The mean daily distance (i.e. distance per tracking day) of each individual was calculated as the ratio between the total distance covered during its radiotracking period and the number of days of the tracking period itself.

To evaluate if body mass is related to dispersal activity and if transmitters hinder the flying activity, we calculated: (i) the correlation between body mass and mean daily distance, (ii) the correlation between the total distance covered flying by each individual and the ratio between transmitter weight and body mass (i.e. transmitter load), and (iii) the difference in the mean transmitter load among beetles which have flown and beetles which have not flown, for males and females separately.

The estimates of spatial utilisation distributions measure the probability of space use throughout an individual home range, allowing calculation of home range area within any desired probability contour (Worton, 1989). The kernel density estimations (KDEs) use nonparametric statistics to calculate the probability of finding an individual in a particular location (Worton, 1989). The individual home range was calculated by the minimum convex polygon (MCP) and by the fixed KDE, where the bandwidth (smoothing parameter) remains constant for all data points (Anderson, 1982; Worton, 1989; Boyle et al., 2009). The MCPs were provided using QGIS ver. 2.6.0, Brighton. The KDE values were calculated with the plugin bandwidth estimator algorithm, a second-generation method which controls for the sample size issue (Gitzen \& Millspaugh, 2003; Beyer, 2012), using the software ArcGIS spatial analyst: GIS by ESRI ver. 10.1 (ESRI, 2011), $\mathrm{R}$ ver. 2.12.1 ( $\mathrm{R}$ Development Core Team, 2010), and geospatial modelling environment ver. 0.7.2.1 (Beyer, 2012). The KDE was modelled using $95 \%$ probability of use for the whole volume size contours and using 50\% probability of use for the core-range size volume contours (Horner \& Powell, 1990; Powell, 2000).

Home range sizes (in terms of $\mathrm{MCP}$ and $\mathrm{KDE}$ ) and total distances (expressed as straight distance between the release point of an individual and the last georeferenced point where it was relocalised) were compared with 
assumed distributions to predict the spatial requirements in terms of area needed and total distances covered by different cumulative proportions of individuals. The assumed distributions tested were negative exponential function, $P=e^{(-D / k)}$; power function, $P=a D^{-n}$; sigmoid function, $P=1-e^{-a e^{(-b D)}}$; exponential function two parameters, $P=a e^{-b D}$; power function three parameters, $P=a D^{b}+c$; sigmoid function three parameters, $P=a /\left(1+e^{-(D-c) / b}\right)$; logistic function three parameters, $P=a /\left(1+b e^{(-c D)}\right)$, where $P$ is the probability that an individual exceeds the distance $D$ (or the home range size) while $a, b, c, n$, and $k$ are constants (Paradis et al., 2002; Kuras et al., 2003; Ranius, 2006; Rink \& Sinsch, 2007; Systat Software, Inc., 2008; Svensson et al., 2011; Chiari et al., 2013b; Zauli et al., 2014).

The initial parameter values of each tested function might not at all reflect the final values, but they were approximate enough to prevent the curve fitter from finding false or invalid results; these values were firstly estimated with the software SigmaPlot ver. 11.0 (Systat Software Inc, 2008) and then calculated with the software R ver. 3.2.2 (R Development Core Team, 2015). The models with lowest AIC (Akaike information criterion) were retained as most explanatory of variance (Borcard et al., 2011). The AIC values were calculated with $\mathrm{R}$ ver. 3.2.2 ( $\mathrm{R}$ Development Core Team, 2015). Only fitting models were reported; models with $\triangle \mathrm{AIC}<2$ were considered equally valid.

To test the hypothesis that dispersal activities mostly occur in the initial part of the adult life span, two groups of variables were examined: (i) the differences between beetles captured by emergence traps (NEB) and those caught by other methods (unknown emergence beetles, hereafter UEB) during the 2015 flight season; (ii) the differences between the first and the second half of the tracking period of each individual (only for NEB males and females).

To compare dispersal patterns and home ranges during the flight season, the latter was divided in three intervals, corresponding to different phases of the species phenology in the study area (Bardiani et al., 2017): (i) from last days of May to15th June, (ii) from 16th to 30th June, (iii) from 1st July to 24th July, and each beetle was assigned to the interval when it was captured. Thus, when a beetle was captured in the last days of an interval, even though its life occurred mostly in the subsequent interval, it was considered to belong to the first one. The analysis was developed for the sexes separately to detect sexual differences in the use of space during the season and to avoid possible interference due to different behaviour between the sexes. Furthermore, the analysis was performed also for the sexes together to investigate on the space use variation by the species throughout the season.

To test the data distribution, the Shapiro test was used. Data were examined with the following methods: MannWhitney $U$-test, Fisher's exact test, Student's $t$-test, Spearman's rank correlation coefficient, Kruskal-Wallis test, Mann-Whitney pairwise test, and AnOva test. Considered variables are listed below: individual radio-tracking period, total distance covered during individual radio- tracking period (i.e. total distance), longest dispersal distance in a single relocation (i.e. maximum distance), flight length, relocation length, total distances covered flying, number of relocations, number of flights, distance per tracking day, MCP and KDE. Details on statistical analyses are reported in Data $\mathrm{S} 1$.

When not differently specified, analyses were performed with PAST - PAlaeontological STatistics, ver. 2.17 (Hammer et al., 2001), using a significance level of 0.05 to reject the null hypothesis.

Zero values were excluded from the subsequent analyses: flight length, relocation length, total distance flying, number of relocations, number of flights, distance per tracking day, MCP, and KDE.

\section{Results}

Capture data and tracking period

In 2014 and 2015, 26 (14 males and 12 females) and 29 stag beetles (20 males and 9 females) were, respectively, radio-tagged.

The Spearman's rank correlation coefficient did not show significant correlation between mean daily distance and body mass (range: 1.4-7.2 g) nor between the total distances covered by flight and the transmitter load in both sexes (Table 1a). The mean transmitter load was $16 \%$ (range: 6-32\%) in flying males, 19\% (11-24\%) in non-flying males, $17 \%(11-25 \%)$ in flying females, and $22 \%$ (16$26 \%$ ) in non-flying females, and the Student's $t$-test showed that the mean transmitter load differed significantly only in females (Table 1a). The radio-tracking period of the individuals (55 on the whole) varied between 1 and 35 days (median 10 days), with no difference between sexes (Table 1b). Only once the transmitter was replaced on one female because of the end of battery. Eleven percent of individuals $(5 / 55)$ were lost because the battery life ended before the death of the beetles or because the beetles might have flown outside the detection range. In several cases, the radio-signal ceased (19/50 all males) for unknown reasons, but the beetles were found nearby the last recorded location. Other individuals (14/50, all females) remained underground for long time and did not emerge again, probably because they were ovipositing. On a number of occasions $(10 / 50)$, transmitters were found without beetles. Finally, a minority of beetles died before the end of the battery $(2 / 50$ by predation: remains were found near the transmitter; $5 / 50$ for unknown reasons: dead beetles were found with transmitter still attached, and one of these was found dead 1 day after the release, very close to the release point, thus it was not taken into account for most of the analyses).

\section{Detection of larval development sites}

The radio-telemetry study carried out in 2014 allowed to detect 21 potential oviposition sites. These results were 
Table 1. Differences between males and females. (a) Correlations between distance per tracking day and body mass, total distance flying and transmitter load, mean transmitter load between flying and non-flying individuals $\left(r_{\mathrm{s}}\right.$, Spearman's rank correlation coefficient; $t$, Student's $t$-test; $P, P$ value). (b) Median or mean values for parameters describing movements and home range ( $U$, Mann-Whitney $U$-test; $t$, Student's $t$-test; $P, P$ value).

\begin{tabular}{|c|c|c|c|c|c|c|c|c|}
\hline \multirow{2}{*}{ (a) } & & \multicolumn{3}{|l|}{ Males } & & \multicolumn{3}{|l|}{ Females } \\
\hline & & $r_{\mathrm{s}}$ & $t$ & $P$ & & $r_{\mathrm{s}}$ & $t$ & $P$ \\
\hline \multirow{3}{*}{\multicolumn{2}{|c|}{$\begin{array}{l}\text { Distance per tracking day/body mass } \\
\text { Total distances flying/transmitter load } \\
\text { Mean transmitter load flying/non-flying individuals }\end{array}$}} & \multirow{3}{*}{$\begin{array}{r}0.173 \\
-0.316\end{array}$} & \multirow[b]{3}{*}{-1.48} & 0.360 & & \multirow{3}{*}{$\begin{array}{r}0.406 \\
-0.436\end{array}$} & \multirow[b]{3}{*}{-17.51} & 0.100 \\
\hline & & & & 0.089 & & & & 0.070 \\
\hline & & & & 0.084 & & & & 0.003 \\
\hline (b) & Males & & Females & & $U$ & & $t$ & $P$ \\
\hline Radio-tracking period (days) & $10(34)$ & & $11(21)$ & & 310 & & & 0.414 \\
\hline Total distance $(\mathrm{m})$ & $191(34)$ & & $63(21)$ & & 168 & & & 0.031 \\
\hline Maximum distance (m) & $88(34)$ & & $36(21)$ & & 183 & & & 0.065 \\
\hline Flight length (m) & $49(27)$ & & $39(13)$ & & 1462 & & & 0.197 \\
\hline Relocation length (m) & $39(30)^{*}$ & & $37(18)^{*}$ & & & & 0.07 & 0.943 \\
\hline Total distance flying (m) & $250(27)^{*}$ & & $170(13)^{*}$ & & & & 1.49 & 0.144 \\
\hline Number of relocations & $7(30)^{*}$ & & $4(18)^{*}$ & & & & 2.94 & 0.005 \\
\hline Number of flights $(>20 \mathrm{~m})$ & $3(27)$ & & $2(13)$ & & 128 & & & 0.167 \\
\hline Distance per tracking day $(\mathrm{m})$ & $25(30)^{*}$ & & $11(18)^{*}$ & & & & 3.42 & 0.001 \\
\hline MCP $\left(\mathrm{m}^{2}\right)$ LogNorm & $7585(28)^{*}$ & & $3471(12)^{*}$ & & & & 0.79 & 0.432 \\
\hline $\operatorname{KDE} 95 \%\left(\mathrm{~m}^{2}\right)$ & $14487(11)$ & & $9500(6)$ & & 28 & & & 0.651 \\
\hline $\operatorname{KDE} 50 \%\left(\mathrm{~m}^{2}\right)$ & $3838(11)$ & & $3414(6)$ & & 22 & & & 0.291 \\
\hline
\end{tabular}

The number of individuals $(N)$ on which the test is based is reported in parenthesis. Relocation length: distance between consecutive georeferenced points. Mean values are reported with asterisk $(*)$.

$\mathrm{MCP}$, minimum convex polygon; KDE, kernel density estimation.

obtained observing the behaviour of eight females, as explained in methods. A mean value of 2.5 oviposition sites per female was recorded. During 2015, one-third $(33 \%)$ of the nine sites where emergence traps were set turned out suitable for larval development (eight males and three females were captured from three traps placed on Quercus spp. during five different checks). Two of these individuals (one male and one female) have not been radio-tagged because not healthy.

\section{Dispersal patterns}

A total dispersal range exceeding $5 \mathrm{~m}$ was recorded in $88 \%$ of males $(30 / 34)$ and in $86 \%$ of females $(18 / 21)$ showing a not significant difference between the sexes (Fisher's exact test, $P=1$ ). Flight events took place from 28th of May to 21st of July. Flights were recorded in $79 \%$ of males $(27 / 34)$ and $62 \%$ of females (13/21), with no difference among the sexes (Fisher's exact test, $P=0.215)$. The mean total distance covered during the individual radio-tracking period was $250 \mathrm{~m}$ for males and $144 \mathrm{~m}$ for females. The medians of total distances covered during the radio-tracking period and the mean distance per tracking day were significantly greater in males than in females (Table 1b). The number of relocations (excluding zero values) ranged from 1 to 17 for males and 1 to 16 for females, and the mean turned out significantly higher in males (Table 1b). Sexes did not differ for other variables (Table 1b).

\section{Home ranges and dispersal ability}

There was no significant difference between sexes in MCP and KDE size (Table 1b) nor in the MCP model ranking: the top-ranked model was the power function three parameters (Fig. 1a, b; Table 2). Sexes differed in the KDE model ranking: for males, the most explanatory model was the logistic function three parameters, while for females was the exponential function two parameters (Fig. 1c-f; Table 2).

Sexes differed in the ranking of dispersal distance models: for males the top fitting model was the sigmoidal function three parameter, while for females, it was the exponential two parameters (Fig. 1g-h; Table 2). Some examples of home ranges computed by $\mathrm{MCP}$ and $\mathrm{KDE}$ methods are given in Figs 2 and 3. Details on prediction of home range size (for both MCP and KDE) and dispersal distance, in males and females, are given in Data S2.

\section{$N E B$ versus $U E B$ and early flights}

The dispersal rate of NEB was $78 \%(7 / 9)$ and that of UEB was $85 \%(17 / 20)$. Of the seven NEB males, only four flew at least once during their radio-tracking period 

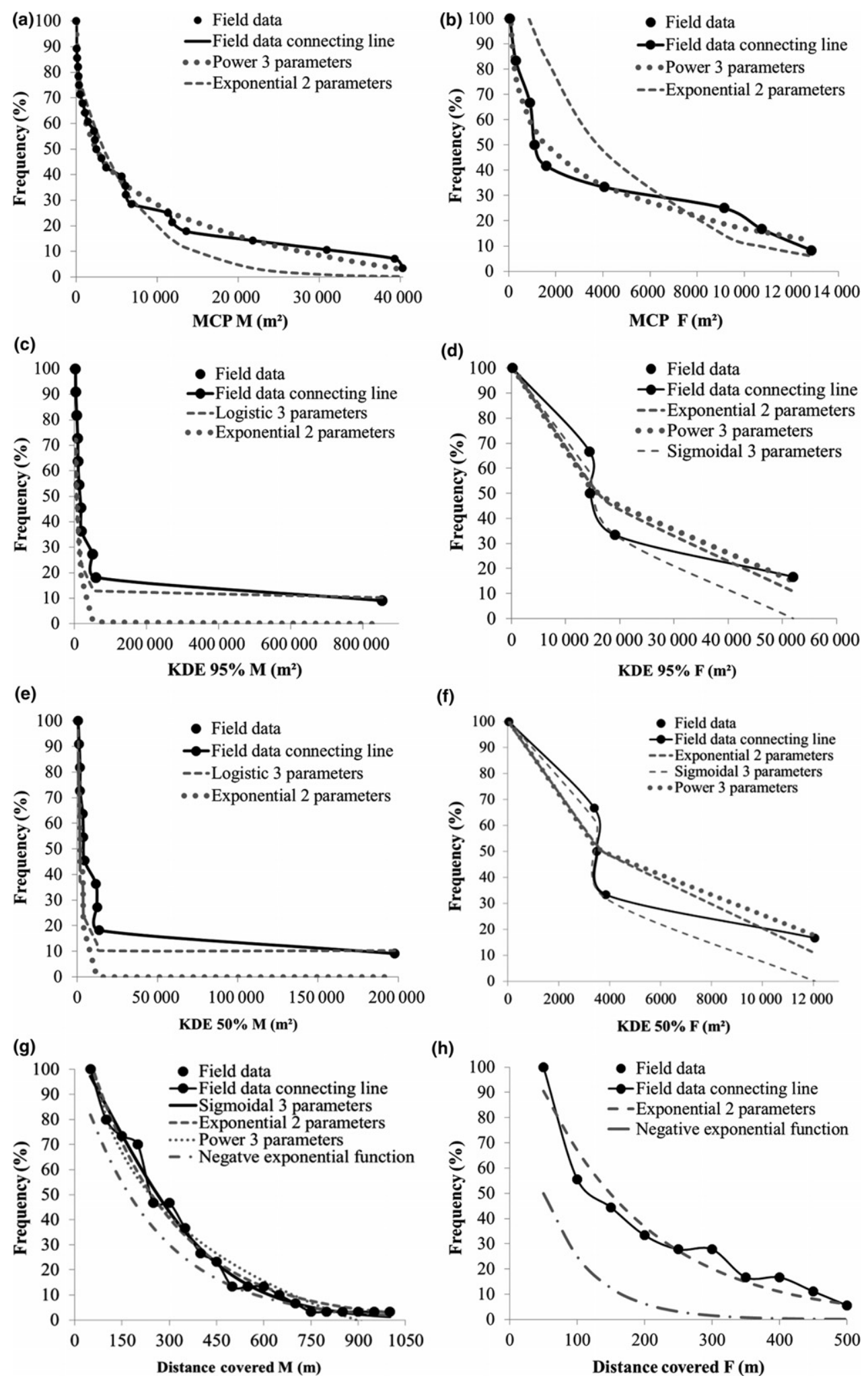

Fig. 1. Models of home range size and dispersal distances in male and female stag beetles. Relation between the frequency of males (M) and females $(\mathrm{F})$, and home range size (a-f) calculated by minimum convex polygon (MCP) and kernel density estimation (KDE $95 \%$ and $50 \%$ ); relation between the frequency of ' $\mathrm{M}$ ' and ' $\mathrm{F}$ ', and dispersal distances covered $(\mathrm{g}-\mathrm{h})$. 
Table 2. Ranking of home ranges and dispersal distance models, using the Akaike information criterion (AIC and its delta value).

\begin{tabular}{|c|c|c|c|c|c|}
\hline & Sex & $\begin{array}{l}\text { Number of } \\
\text { individuals }\end{array}$ & Model & AIC & $\Delta \mathrm{AIC}$ \\
\hline \multirow[t]{4}{*}{ MCP } & \multirow[t]{2}{*}{$\sigma^{7}$} & \multirow[t]{2}{*}{28} & Power 3 parameters & 133.14 & 0 \\
\hline & & & Exponential 2 parameters & 178.48 & 45.34 \\
\hline & \multirow[t]{2}{*}{ 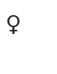 } & \multirow[t]{2}{*}{12} & Power 3 parameters & 63.92 & 0 \\
\hline & & & Exponential 2 parameters & 75.13 & 11.21 \\
\hline \multirow[t]{5}{*}{ KDE $95 \%$} & \multirow[t]{2}{*}{$\sigma^{7}$} & \multirow[t]{2}{*}{11} & Logistic 3 parameters & 65.28 & 0 \\
\hline & & & Exponential 2 parameters & 79.47 & 14.19 \\
\hline & \multirow[t]{3}{*}{ } & \multirow[t]{3}{*}{6} & Exponential 2 parameters & 41.11 & 0 \\
\hline & & & Power 3 parameters & 43.63 & 2.52 \\
\hline & & & Sigmoidal 3 parameters & 44.23 & 3.12 \\
\hline \multirow[t]{5}{*}{ KDE $50 \%$} & \multirow[t]{2}{*}{$\sigma^{7}$} & \multirow[t]{2}{*}{11} & Logistic 3 parameter & 72.51 & 0 \\
\hline & & & Exponential 2 parameter & 81.28 & 8.77 \\
\hline & \multirow[t]{3}{*}{ q } & \multirow[t]{3}{*}{6} & Exponential 2 parameter & 42.87 & 0 \\
\hline & & & Sigmoidal 3 parameter & 43.13 & 0.26 \\
\hline & & & Power 3 parametric & 44.87 & 2 \\
\hline \multirow[t]{6}{*}{ Dispersal distance } & \multirow[t]{4}{*}{$\sigma^{*}$} & \multirow[t]{4}{*}{30} & Sigmoidal 3 parameter & 108.76 & 0.00 \\
\hline & & & Exponential 2 parameter & 117.97 & 9.20 \\
\hline & & & Power 3 parameter & 131.35 & 22.58 \\
\hline & & & Negative exponential & 208.63 & 99.87 \\
\hline & \multirow[t]{2}{*}{ q } & \multirow[t]{2}{*}{18} & Exponential 2 parameter & 70.41 & 0.00 \\
\hline & & & Negative exponential & 106.54 & 36.13 \\
\hline
\end{tabular}

Home ranges were calculated for males and females by minimum convex polygon (MCP) and kernel density estimation (KDE $95 \%$ and $50 \%$ ).

(4/7: $57 \%$ ) and of the 13 UEB males, 10 flew at least once during their tracking period (10/13: $77 \%)$. The only two NEB females have not flown during their tracking period $(20$ and 13 days), while 5/7 (71\%) UEB females have flown. The rate of dispersing and flying beetles did not differ between the two categories (Fisher's exact test, $P=0.095$ ). The first male captured within an emergence trap (whose home ranges are represented in Fig. 2a) reached the greatest total distance flying covered by one individual $(903 \mathrm{~m}$ with 8 flights in 11 days) and a high significant difference occurred for the mean total distance covered flying (Table 3). The greatest MCP was calculated for a UEB male, while the greatest values of KDE were calculated for a NEB male (Fig. 2c). Despite that, the two groups did not differ for the mean values of home range sizes nor for other variables (Student's $t$ test $P>0.05$ ) (Table 3 ).

Of the four NEB males that have flown, the longest flight occurred in the first half of their radio-tracking period of two males $(50 \%)$, while the two NEB females did not fly. The medians of the relocation length turned out higher during the first half of the tracking period $(25 \mathrm{~m}$ for the first half, and $16 \mathrm{~m}$ for the second half; MannWhitney $U$-test: $U=5152.50, P=0.005)$; the medians of the number of relocations and of the number of flights during the first half ( 3 and 2, respectively) resulted higher than those of the second half (1 and 0 , respectively; $U=946, P=0.016 ; U=314, P<0.01)$.

\section{Use of space in relation to the flight season}

The analysis developed for males and females separately did not show significant differences among the three intervals, except for the median number of relocations of males (Table 4). A higher number of relocations concerned with males captured during the first interval (Kruskal-Wallis test: $H=7.33, P=0.024$; Mann-Whitney pairwise $P=0.028 ; P=0.028$ ) (Table 4). On the contrary, the medians of the flight length for the individuals captured in the second interval resulted higher than the medians of the first one $(H=6.49, P=0.039$; MannWhitney pairwise, $P=0.013)$. The medians of the number of relocations and of the number of flights resulted higher for the individuals captured in the first interval than for the individuals of the second one (Kruskal-Wallis test: $H=7.15, P=0.027 ; H=6.32, P=0.038$; Mann-Whitney pairwise $P=0.012 ; P=0.017$ ) (Table 4$)$. The greatest MCP $\left(40285 \mathrm{~m}^{2}\right)$ was calculated for a male captured during the first interval. On the contrary, the greatest values of $\mathrm{KDE} 95 \%$ and $\mathrm{KDE} 50 \%$ (853339 and $197751 \mathrm{~m}^{2}$, respectively) were estimated for a male captured in the second interval (Fig. 2c). No significant difference was found between the three intervals for the home range sizes, nor for other variables (Table 4).

\section{Discussion}

\section{Detection of larval development sites}

Radio-telemetry resulted a suitable method to detect oviposition sites for stag beetles. The detection of oviposition sites during the first study year allowed us to radiotag individuals before their first flight during the second study year, which was mainly dedicated to compare dispersal patterns and home ranges among different 

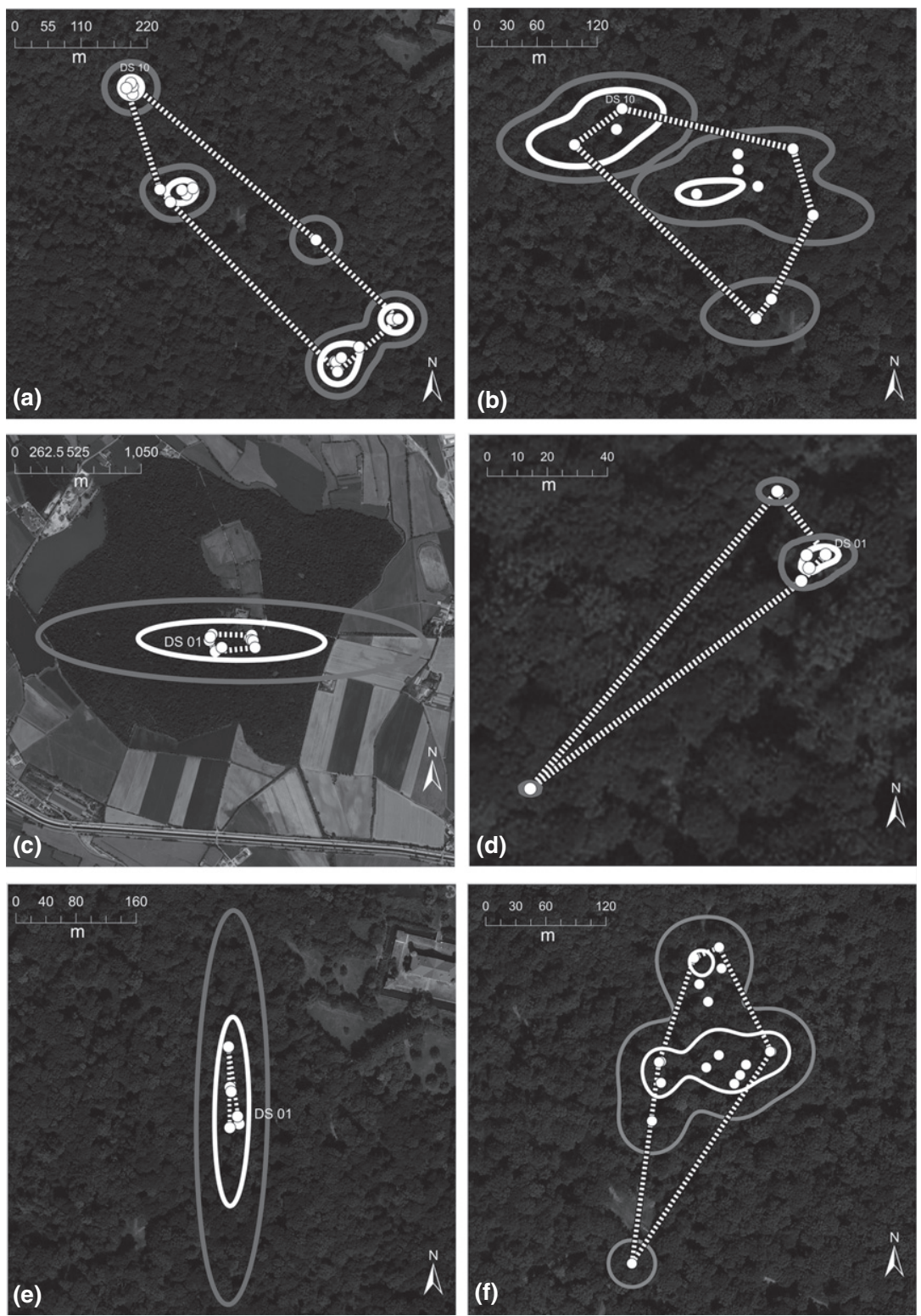

Fig. 2. Home range size of three males ( $a, c, e)$ and three females (b, d, f) of stag beetle. The dashed line indicates the minimum convex polygon perimeter; the solid grey and white lines represent the kernel density estimation $95 \%$ and $50 \%$, respectively. DS, development site.

categories (NEB and UEB, males and females). Furthermore, the capture of individuals with emergence traps gave us the opportunity to investigate the space use without losing the first part of the beetles' life span and to obtain information on their first flights.

\section{Dispersal patterns and home ranges}

The mean daily distance of each individual was not related to their body mass. The transmitter load was not a hindrance to fly for both sexes, and the difference in the mean transmitter load between flying and non-flying females may be probably due to chance.

In our study, as well as in Alf and Bullay, the German locality studied by Rink and Sinsch (2007), the higher proneness to dispersal of males was suggested by the higher median values of the total distance covered during the individual tracking period, and by the mean distance per tracking day. Moreover, we inferred that also the higher number of relocations observed for males during their tracking period led to the same conclusion.

(C) 2017 The Royal Entomological Society, Insect Conservation and Diversity, 11, 116-129 

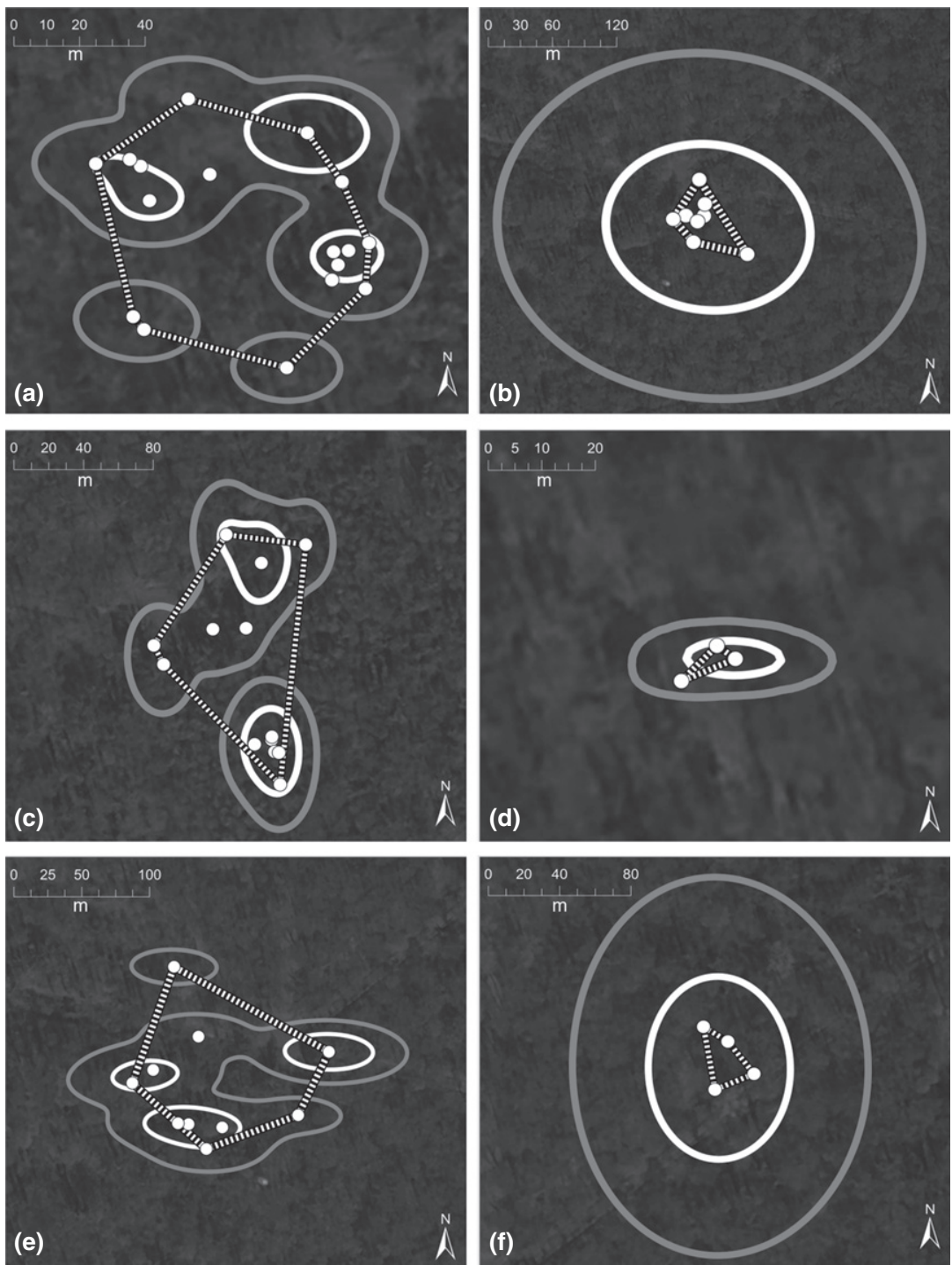

Fig. 3. Further illustrations of home range size of three males (a, c, e) and three females (b, d, f) of stag beetle. The dashed line indicates the minimum convex polygon perimeter; the solid grey and white lines represent the kernel density estimation $95 \%$ and $50 \%$, respectively.

Although the home ranges size was not significantly different between the sexes, the different ranking in KDE models showed a logistic decay for males and an exponential decay for females in the frequency of the individuals in relation to their home range size $(\%$ of the maximum home range size). For males, the highest values of KDE $(95 \%$ and $50 \%)$ were much higher than those of the half of the individuals. For females, the difference between the highest mean values was not as great as in males.

The ranking of dispersal distance models indicated an exponential decay for females, while the top fitting model for males was a sigmoid function. The latter suggested that, over short distances, the dispersal probability tends to decrease in a gradual but distinct way. Indeed, the sigmoid model combines the initial flat decline with an exponential decrease over long distances (Kuras et al., 2003; Heinz et al., 2005). These results confirm previous observations of the telemetric study developed at Alf and Bullay by Rink and Sinsch (2007): a small percentage of males showed a very much higher dispersal distance than the average of most individuals. The dispersal distance prediction and the percentage of males with higher dispersal ability turned out by our study at Bosco Fontana were lower than at Alf and Bullay. Probably, the ecological conditions of our study area make dangerous or useless for stag beetles to cover long distance by flying. In fact, the high summer temperatures of the Po valley may induce physiological risks for flying beetles. Such a physiological risk for dehydration at high temperature was already hypothesised by Rink and Sinsch (2011), who 
Table 3. Parameters describing movements and home range: differences between new emergence beetles (NEB) and unknown emergence beetles (UEB).

\begin{tabular}{|c|c|c|c|c|c|}
\hline & NEB & UEB & $U$ & $t$ & $P$ \\
\hline Radio-tracking period (days) & $10(9)^{*}$ & $10(20)^{*}$ & & -0.22 & 0.828 \\
\hline Total distance $(\mathrm{m})$ & $14(9)$ & $162(20)$ & 60 & & 0.190 \\
\hline Maximum distance (m) & $68(9)^{*}$ & $81(20)^{*}$ & & -0.95 & 0.351 \\
\hline Flight length (m) & $42(4)$ & $40(16)$ & 297 & & 0.431 \\
\hline Relocation length (m) & $45(7)^{*}$ & $36(17)^{*}$ & & -0.22 & 0.827 \\
\hline Total distance flying (m) & $382(4)^{*}$ & $178(16)^{*}$ & & 4.32 & 0.000 \\
\hline Number of relocations & $2(7)$ & $5(17)$ & 84 & & 0.353 \\
\hline Number of flights $(>20 \mathrm{~m})$ & $5(4)$ & $2(16)$ & 20 & & 0.268 \\
\hline Distance per tracking day $(\mathrm{m})$ & $6(7)$ & $17(17)$ & 73 & & 0.188 \\
\hline $\operatorname{MCP}\left(\mathrm{m}^{2}\right)$ & $10595(5)^{*}$ & $4670(15)^{*}$ & & -0.8 & 0.436 \\
\hline $\operatorname{KDE} 95 \%\left(\mathrm{~m}^{2}\right)$ & $222651(4)^{*}$ & $28151(7)^{*}$ & & -0.07 & 0.946 \\
\hline $\mathrm{KDE} 50 \%\left(\mathrm{~m}^{2}\right)$ & $51532(4)^{*}$ & $6424(7)^{*}$ & & -0.06 & 0.952 \\
\hline
\end{tabular}

Median or mean values are reported. The number of individuals $(N)$ on which the test is based is reported in parenthesis. Relocation length: distance between consecutive georeferenced points. Mean values are reported with asterisk $(*)$.

$U$, Mann-Whitney $U$-test; $t$, Student's $t$-test; $P, P$ value; MCP, minimum convex polygon; KDE, kernel density estimation.

noticed a lower flying activity of stag beetles in the warmest years of Germany.

In Italy, where very high temperatures are usual in summer, the flying activity is ruled by a balance between the dehydration risk and the reproductive success (more access to mates and oviposition sites). A series of environmental factors occurring at Alf and Bullay, such as the scattered distribution of oviposition sites and the more favourable (cooler and wetter) weather conditions in the summer of central Europe, may explain the longer distances covered by stag beetles (particularly by males) and the higher percentage of males expected to cover longer distances (Rink \& Sinsch, 2007). Probably, the females of Bosco Fontana are favoured by the dead wood abundance in this forest because they do not need to fly much for finding a suitable oviposition site. Moreover, the absence of flights performed by NEB females may support the hypothesis that they have not much to walk to get a suitable oviposition site. Partial egg retention by females (proved by the emerging fact that some single females laid eggs more than once) was a nest site colonisation strategy suggested by $6(75 \%)$ of the eight radio-tagged females which dug deeply in more than one site. Egg retention was already observed in previous studies for O. eremita, another large saproxylic beetle of high conservation priority (Dubois et al., 2010; Svensson et al., 2011).

\section{$N E B$ versus $U E B$ and early flights}

The difference in the mean total distance covered flying between NEB and UEB males confirmed the hypothesis of Rink and Sinsch (2007), that stag beetle males are more prone to dispersal activities during the initial part of their adult life and that the first half of the adult lifetime is really crucial to get valid information on the use of space by the species.
Even in the males of Bosco Fontana, the distances covered, the number of relocations, and the number of flights turned out higher during the first half of the individual tracking period. Therefore, the stag beetles are more active in their initial adult phase, and all studies on dispersal and space use should start as soon as possible after adult emergence. The main reason for NEB and UEB beetles did not show marked differences in dispersal activity, except the total distance flying, is likely due to the high probability that UEBs were captured soon after their emergence (a very probable hypothesis because almost all UEBs were captured in flight, thus in full dispersal activity).

\section{Use of space in relation to the flight season}

The individuals captured during the first interval of the season (first half of June) showed a higher number of relocations and of flights, but lower values of flight length.

The individuals captured during the second interval of the season (second half of June) showed the lowest number of relocations and of flights, but higher values of flight length.

The individuals captured during the third interval of the season (first half of July) showed intermediate values of the three parameters above mentioned. The values of all other parameters were not significantly different (Table 4).

These results may be explained as an initial phase of exploration of the neighbourhood to find mates, avoiding to engage in more dangerous surveys full of risks due to predation and dehydration. On the contrary, a second phase seems to be characterised by longer trips to favour dispersal and gene flux, after a basic reproductive success (close to the natal area) was ensured. Longer trips could also be related to the higher competition due to the 
Table 4. Differences in parameters describing movements and home range between the individuals (males, females, males + females) captured during the three intervals of the season: (i) from last days of May to15th June, (ii) from 16th to 30th June, (iii) from 1st July to 24th July.

\begin{tabular}{|c|c|c|c|c|c|c|}
\hline & \multicolumn{3}{|l|}{ Intervals } & \multicolumn{2}{|c|}{ Kruskal-Wallis/ANOVA } & \multirow{2}{*}{$\begin{array}{l}\text { Mann-Whitney pairwise } \\
P\end{array}$} \\
\hline & 1 & 2 & 3 & $H / F$ & $P$ & \\
\hline \multicolumn{7}{|l|}{ Males } \\
\hline Radio-tracking period (days) & $11(13)$ & $8(10)$ & $8(11)$ & 5.57 & 0.060 & - \\
\hline Total distance $(\mathrm{m})$ & $302(13)$ & $168(10)$ & $129(11)$ & 2.01 & 0.365 & - \\
\hline Maximum distance $(\mathrm{m})$ & $82(13)$ & $114(10)$ & $65(11)$ & 0.07 & 0.965 & - \\
\hline Flight length (m) & $50(11)^{*}$ & $40(7)^{*}$ & $48(9)^{*}$ & 0.06572 & 0.936 & - \\
\hline Relocation length (m) & $40(12)^{*}$ & $32(8)^{*}$ & $43(10)^{*}$ & 0.8978 & 0.409 & - \\
\hline Total distance flying (m) & $276(11)$ & $146(7)$ & $129(9)$ & 1.52 & 0.467 & - \\
\hline Number of relocations (m) & $9(12)$ & $5(8)$ & $6(10)$ & 7.33 & 0.024 & 0.028 \\
\hline Number of flights $(>20 \mathrm{~m})$ & $5(11)$ & $3(7)$ & $2(9)$ & 3.93 & 0.133 & - \\
\hline Distance per tracking day (m) & $18(12)$ & $14(8)$ & $28(10)$ & 1.10 & 0.577 & - \\
\hline $\operatorname{MCP}\left(\mathrm{m}^{2}\right)$ & $9834(12)^{*}$ & $4847(7)^{*}$ & $6716(9)^{*}$ & 0.4274 & 0.657 & - \\
\hline $\mathrm{KDE} 95 \%\left(\mathrm{~m}^{2}\right)$ & $9107(7)$ & $50133(3)$ & $2607(1)$ & 4.49 & 0.106 & - \\
\hline $\mathrm{KDE} 50 \%\left(\mathrm{~m}^{2}\right)$ & $1847(7)$ & $11642(3)$ & $584(1)$ & 4.33 & 0.115 & - \\
\hline \multicolumn{7}{|l|}{ Females } \\
\hline Radio-tracking period (days) & $13(7)$ & $11(8)$ & $11(6)$ & 0.23 & 0.891 & - \\
\hline Total distance $(\mathrm{m})$ & $116(7)$ & $20(8)$ & $54(6)$ & 0.50 & 0.776 & - \\
\hline Maximum distance (m) & $39(7)$ & $16(8)$ & $33(6)$ & 0.28 & 0.869 & - \\
\hline Flight length $(\mathrm{m})$ & $38(5)$ & $40(3)$ & $39(5)$ & 0.60 & 0.739 & - \\
\hline Relocation length (m) & $28(6)^{*}$ & $57(7)^{*}$ & $25(5)^{*}$ & 2.97 & 0.058 & - \\
\hline Total distance flying $(\mathrm{m})$ & $150(5)$ & $274(3)$ & $39(5)$ & 3.43 & 0.180 & - \\
\hline Number of relocations (m) & $5(6)$ & $2(7)$ & $3(5)$ & 2.40 & 0.284 & - \\
\hline Number of flights $(>20 \mathrm{~m})$ & $4(5)$ & $1(3)$ & $1(5)$ & 2.51 & 0.245 & - \\
\hline Distance per tracking day (m) & $13(6)$ & $3(7)$ & $5(5)$ & 1.37 & 0.504 & - \\
\hline $\operatorname{MCP}\left(\mathrm{m}^{2}\right)$ & $1098(5)$ & $1223(4)$ & $262(3)$ & 2.14 & 0.343 & - \\
\hline $\operatorname{KDE} 95 \%\left(\mathrm{~m}^{2}\right)$ & $14519(3)$ & $202(1)$ & $16778(2)$ & 2.14 & 0.343 & - \\
\hline $\operatorname{KDE} 50 \%\left(\mathrm{~m}^{2}\right)$ & $3478(3)$ & $35(1)$ & $3588(2)$ & 1.12 & 0.571 & - \\
\hline \multicolumn{7}{|l|}{ Males + females } \\
\hline Radio-tracking period (days) & $12(20)$ & $10(18)$ & $10(17)$ & 3.95 & 0.137 & - \\
\hline Total distance $(\mathrm{m})$ & $228(20)$ & $126(18)$ & $78(17)$ & 1.79 & 0.408 & - \\
\hline Maximum distance (m) & $78(20)$ & $89(18)$ & $52(17)$ & 0.14 & 0.934 & - \\
\hline Flight length (m) & $39(16)$ & $46(10)$ & $42(14)$ & 6.49 & 0.039 & 0.013 \\
\hline Relocation length (m) & $20(18)$ & $19(15)$ & $24(15)$ & 0.87 & 0.647 & - \\
\hline Total distance flying (m) & $230(16)$ & $136(10)$ & $86(14)$ & 1.63 & 0.443 & - \\
\hline Number of relocations (m) & $8(18)$ & $2(15)$ & $4(15)$ & 7.15 & 0.027 & 0.012 \\
\hline Number of flights $(>20 \mathrm{~m})$ & $5(16)$ & $2(10)$ & $3(14)$ & 6.32 & 0.038 & 0.017 \\
\hline Distance per tracking day $(\mathrm{m})$ & $16(18)$ & $12(15)$ & $17(15)$ & 1.52 & 0.467 & - \\
\hline $\operatorname{MCP}\left(\mathrm{m}^{2}\right)$ & $3708(17)$ & $1561(11)$ & $801(12)$ & 0.38 & 0.692 & - \\
\hline $\operatorname{KDE} 95 \%\left(\mathrm{~m}^{2}\right)$ & $9304(10)$ & $34781(4)$ & $14456(3)$ & 1.06 & 0.589 & - \\
\hline $\operatorname{KDE} 50 \%\left(\mathrm{~m}^{2}\right)$ & $3455(10)$ & 8067 (4) & 3357 (3) & 1.12 & 0.571 & - \\
\hline $\operatorname{MCP}\left(\mathrm{m}^{2}\right)$ LogNorm & $7832(17)^{*}$ & $4282(11)^{*}$ & $6149(12)^{*}$ & 0.69 & 0.508 & - \\
\hline KDE $95 \%\left(\mathrm{~m}^{2}\right) \operatorname{LogNorm}$ & $17144(10)^{*}$ & $230776(4)^{*}$ & $12054(3)^{*}$ & 0.38 & 0.692 & - \\
\hline
\end{tabular}

The values for each parameter during the three intervals represent the median or mean values. The number of individuals $(N)$ on which the test is based is reported in parenthesis. Relocation length: distance between consecutive georeferenced points. Mean values are reported with asterisk (*).

$H$, Kruskal-Wallis; $F$, ANOva; $P, P$ value; MCP, minimum convex polygon; KDE, kernel density estimation.

abundance peak observed at Bosco Fontana (Bardiani et al., 2017) in the second interval. Home range size variation was not related to the interval in which the beetles were captured. Thus, dispersal activities seem to match the phenology of the species in the study area, as reported by Bardiani et al. (2017), and the variation in abundance of both competitors and mating partners during the flight season.

\section{Conclusion and implications for insect conservation}

The detection of larval development sites and the possibility of radio-tagging newly emerged stag beetles allowed us to gather data on dispersal of the adults during the initial part of their adult life (when they resulted more active). Thus, we got important information on a stag beetle 
population living in an isolated broadleaf lowland forest with a huge content of dead wood. These habitat conditions represent a predictable scenario for many small European conservation areas, now completely surrounded by cultivated land.

Males were more prone to disperse in the first half of their radio-tracking period, and some individuals covered distances up to near $300 \mathrm{~m}$ in a single flight and to about $1 \mathrm{~km}$ during the whole tracking period. Both the total distance covered and the mean distance per tracking day resulted lower in females.

Dispersal patterns resulted to vary throughout the flight season, with a peak of dispersal movements number in the first half of June and longer flights during the second half of June. The higher flying activity observed in the second interval is probably due to the simultaneous emergence of many individuals in a short-time interval and an intensive mating activity favoured by optimal climatic conditions, before of the hot and drier climate of July, when adult stag beetle life turns to the end in the study area.

The unsuitable surrounding environment (an intensively cultivated matrix) and the isolation of the study area probably make hazardous and fruitless the dispersal activity out of the Reserve. Thus, the placement of artificial dead wood heaps outside the Reserve for encouraging stag beetle dispersal, as proposed in other geographical contexts (Dudley \& Vallauri, 2004; Rink \& Sinsch, 2007; Fremlin, 2009; Thomaes, 2009), should be avoided for Bosco Fontana, because of the lack of suitable habitat within a wide radius. In fact, the long distance until the nearest potentially suitable environment makes such kind of interventions counterproductive, transforming the stepping stones into potential sinks. The dispersal behaviour of the stag beetle in Bosco della Fontana suggests that a management focused on the conservation of the complex structure of this old-growth forest ecosystem is the only way to guarantee optimal habitat conditions for the species. Therefore, to ensure long-term conservation of the species, it is desirable the continuation of the current policy of increasing dead wood, maintaining uneven-aged structure and the natural ageing of the trees.

\section{Acknowledgements}

The present paper was supported by the EU project LIFE11 NAT/IT/000252 MIPP 'Monitoring Insects with Public Participation' with the contribution of the LIFE financial instrument of the European Union and by the Regional Park Agency (ARP Lazio) project 'Monitoring of saproxylic and xylophagous insect populations in the protected areas of Latium'. Our greatest thanks are due to Marco Bologna, who was the Coordinator of the MIPP Beneficiary Roma Tre University. We are also grateful to the staff of the National Forest Service at the State Reserve 'Bosco della Fontana', for facilitations and help. A special thank is due to Randi Rollins (Ogden, Utah, USA) who voluntarily helped during the fieldwork in 2014 and to Alice Malavasi for the fieldwork assistance in 2015. We thank Alan Gange and Marcos Méndez for precious advice for the improvement of the manuscript and Agnese Zauli for useful discussion and suggestion.

\section{Supporting Information}

Additional Supporting Information may be found in the online version of this article under the DOI reference: doi: 10.1111/ icad.12260:

Data S1. Details on statistical analyses.

Data S2. Details on prediction of home range size and dispersal distance.

\section{References}

Anderson, D.J. (1982) The home range: a new nonparametric estimation technique. Ecology, 63, 103-112.

Bardiani, M., Tini, M., Carpaneto, G.M., Audisio, P., Bussola, E., Campanaro, A., Cini, A., Maurizi, E., Mason, F., Sabbatini Peverieri, G., Roversi, P.F., Toni, I. \& Chiari, S. (2017) Effects of trap baits and height on stag beetles and flower chafers monitoring: ecological and conservation implications. Journal of Insect Conservation, 21, 157-168.

Beyer, H.L. (2012) Geospatial modelling environment (version 0.7.2.1) < http://www.spatialecology.com/gme > 20th July 2013.

Boiteau, G. \& Colpitts, B. (2001) Electronic tags for the tracking of insects in flight: effect of weight on flight performance of adult Colorado potato beetles. Entomologia Experimentalis et Applicata, 100, 187-193.

Borcard, D., Gillet, F. \& Legendre, P. (2011) Spatial analysis of ecological data. Numerical Ecology with $R$ pp. 227-292. Springer, New York City, New York.

Boyle, S.A., Lourenco, W.C., da Silva, L.R. \& Smith, A.T. (2009) Home range estimates vary with sample size and methods. Folia Primatologica, 80, 33-42.

Campanaro, A., Zapponi, L., Hardersen, S., Méndez, M., Al Fulaij, N., Audisio, P., Bardiani, M., Carpaneto, G.M., Corezzola, S., Della Rocca, F., Harvey, D., Hawes, C., Kadej, M., Karg, J., Rink, M., Smolis, A., Sprecher, E., Thomaes, A., Toni, I., Vrezec, A., Zauli, A., Zilioli, M. \& Chiari, S. (2016) A European monitoring protocol for the stag beetle, a saproxylic flagship species. Insect Conservation and Diversity, 9, 574 584.

Carpaneto, G.M., Baviera, C., Biscaccianti, A.B., Brandmayr, P., Mazzei, A., Mason, F., Battistoni, A., Teofili, C., Rondinini, C., Fattorini, S. \& Audisio, P. (2015) A red list of Italian Saproxylic Beetles: taxonomic overview, ecological features and conservation issues (Coleoptera). Fragmenta Entomologica, 47, $53-126$.

Cavalli, R. \& Mason, F. (2003). Techniques for re-establishment of dead wood for saproxylic fauna conservation. LIFE Nature project NAT/IT/99/6245 'Bosco della Fontana' (Mantova, Italy). Scientific Report 2, Centro Nazionale per lo Studio e la Conservazione della Biodiversità Forestale di Verona - Bosco della Fontana, pp. 1-112, Gianluigi Arcari Editore, Mantova, Italy.

Chiari, S., Bardiani, M., Zauli, A., Hardersen, S., Mason, F., Spada, L. \& Campanaro, A. (2013a) Monitoring of the 
saproxylic beetle Morimus asper (Sulzer, 1776) (Coleoptera: Cerambycidae) with freshly cut log piles. Journal of Insect Conservation, 17, 1255-1265.

Chiari, S., Carpaneto, G.M., Zauli, A., Zirpoli, G.M., Audisio, P. \& Ranius, T. (2013b) Dispersal patterns of a saproxylic beetle, Osmoderma eremita, in Mediterranean woodlands. Insect Conservation and Diversity, 6, 309-318.

Chiari, S., Zauli, A., Audisio, P.A., Campanaro, A., Donzelli, P.F., Romiti, F., Svensson, G.P., Tini, M. \& Carpaneto, G.M. (2014) Monitoring presence, abundance and survival probability of the stag beetle, Lucanus cervus, using visual and odourbased capture methods: implications for conservation. Journal of Insect Conservation, 18, 99-109.

Clark, J.T. (1977) Aspects of variation in the stag beetle Lucanus cervus L. (Coleoptera: Lucanidae). Systematic Entomology, 2, 9-16.

Dubois, G. \& Vignon, V. (2008) First results on radio-tracking of Hermit beetle, Osmoderma eremita (Coleoptera: Cetoniidae) in chestnut orchards of the northwest of France. Revue D'Écologie - La Terre et La Vie, 63, 123-130.

Dudley, N. \& Vallauri, D. (2004) Deadwood-living forests: the importance of veteran trees and deadwood to biodiversity. World Wide Fund for Nature (WWF) Report - October 2004, Gland, Switzerland, pp. 1-19.

ESRI (2011) ArcGIS Desktop: Release 10.1. Environmental Systems Research Institute, Redlands, California.

Fremlin, M. (2009) Stag beetle (Lucanus cervus, (L., 1758), Lucanidae) urban behaviour. In Saproxylic beetles. Their role and diversity in European woodland and tree habitats. Proceedings of the 5th Symposium and Workshop on the Conservation of Saproxylic Beetles, 89, 161-176.

Gitzen, R.A. \& Millspaugh, J.J. (2003) Comparison of leastsquares cross-validation bandwidth options for kernel homerange estimation. Wildlife Society Bulletin, 31, 823-831.

Hammer, Ø., Harper, D.A.T. \& Ryan, P.D. (2001) Past: paleontological statistics software package for education and data analysis. Palaeontologia Electronica, 4, 1-9. < http://palaeo-elec tronica.org/2001_1/past/issue1_01.htm.> 13th May 2001.

Harvey, D.J. \& Gange, A.C. (2003) The private life of the stag beetle. The Bulletin of the Amateur Entomologists' Society, 62, 240-244.

Harvey, D.J., Gange, A.C., Hawes, C.J., Rink, M., Abdehalden, M., Al-Fulaij, N., Asp, T., Ballerio, A., Bartolozzi, L., Brustel, H., Cammaerts, R., Carpaneto, G., Cederberg, B., Chobot, K., Cianferoni, F., Drumont, A., Ellwanger, G., Ferreira, S., Grosso-Silva, J., Gueorguiev, B., Harvey, W., Hendriks, P., Istrate, P., Jansson, N., Jelaska, L., Jendek, E., Jovic, M., Kervyn, T., Krenn, H., Kretschmer, K., Legakis, A., Lelo, S., Moretti, M., Merkl, O., Mader, D., Palma, R., Neculiseanu, Z., Rabitsch, W., Rodrıguez, S., Smit, J., Smith, M., SprecherUebersax, E., Telnov, D., Thomaes, A., Thomsen, P., Tykarski, P., Vrezec, A., Werner, S. \& Zach, P. (2011a) Bionomics and distribution of the stag beetle, Lucanus cervus (L) across Europe. Insect Conservation and Diversity, 4, 23-38.

Harvey, D.J., Hawes, C.J., Gange, A.C., Finch, P., Chesmore, D. \& Farr, I. (2011b) Development of non-invasive monitoring methods for larvae and adults of the stag beetle, Lucanus cervus. Insect Conservation and Diversity, 4, 4-14.

Hassel, M.P. (1987) Detecting regulation in patchily distributed animal populations. Journal of Animal Ecology, 56, 705-731.

Heinz, S.K., Conradt, L., Wissel, C. \& Frank, K. (2005) Dispersal behaviour in fragmented landscapes: deriving a practical formula for patch accessibility. Landscape Ecology, 20, 83-99.
Horner, M.A. \& Powell, R.A. (1990) Internal structure of home range of black bears: an analyses of home range overlap. Journal of Mammalogy, 71, 402-410.

Kuras, T., Benes, J., Fric, Z. \& Konvicka, M. (2003) Dispersal patterns of endemic alpine butterflies with contrasting population structures: Erebia epiphron and E. sudetica. Population Ecology, 45, 115-123.

Manly, B.F.L., McDonald, L., Thomas, D., McDonald, T.L. \& Erickson, W.P. (2007) Resource Selection by Animals: Statistical Design and Analysis for Field Studies. Springer Science \& Business Media, Dordrecht, the Netherlands.

Mason, F. (2004) Dinamica di una foresta della Pianura Padana. Bosco della Fontana. Seconda edizione con linee di gestione forestale. Scientific Report 1, Centro Nazionale Biodiversità Forestale Verona - Bosco della Fontana, pp. 1-224, Gianluigi Arcari Editore, Mantova, Italy.

Mason, F., Roversi, P.F., Audisio, P., Bologna, M.A., Carpaneto, G.M., Antonini, G., Mancini, E., Sabbatini Peverieri, G., Mosconi, F., Solano, E., Maurizi, E., Maura, M., Chiari, S., Sabatelli, S., Bardiani, M., Toni, I., Redolfi De Zan, L., Rossi De Gasperis, S., Tini, M., Cini, A., Zauli, A., Nigro, G., Bottacci, A., Hardersen, S. \& Campanaro, A. (2015) Monitoring of insects with public participation (MIPP; EU LIFE project 11 NAT/IT/000252): overview on a citizen science initiative and a monitoring programme (Insecta: Coleoptera; Lepidoptera; Orthoptera). Fragmenta Entomologica, 47, 51-52.

Morris, D.W. (2003) Toward an ecological synthesis: a case for habitat selection. Oecologia, 136, 1-13.

Nieto, A. \& Alexander, K.N.A. (2010) European Red List of Saproxylic Beetles. Publications Office of the European Union, Spain, Mijas (Malaga).

Paradis, E., Baille, S.R. \& Southerland, W.J. (2002) Modeling large-scale dispersal distances. Ecological Modelling, 151, 279292.

Pearman, P.B. \& Wilbur, H.M. (1990) Changes in population dynamics resulting from oviposition in a subdivided habitat. American Naturalist, 135, 708-723.

Powell, R.A. (2000) Animal home ranges and territories and home range estimators. Research Techniques in Animal Ecology: Controversies and Consequences, (ed. by L. Boitani and T.K. Fuller), pp. 1-442. Columbia University Press, New York City, New York.

QGIS Development Team (2014) QGIS geographic information system. Open Source Geospatial Foundation Project. < http:// www.qgis.org/ > 1st November 2014.

R Development Core Team (2010) R: A Language and Environment for Statistical Computing. R Foundation for Statistical Computing. < http://www.r-project.org > 15th October 2010.

R Development Core Team (2015) R: A Language and Environment for Statistical Computing. R Foundation for Statistical Computing. < http://www.r-project.org > 14th August 2015.

Ranius, T. (2006) Measuring the dispersal of saproxylic insects: a key characteristic for their conservation. Population Ecology, 48, 177-188.

Rink, M. \& Sinsch, U. (2007) Radio-telemetric monitoring of dispersing stag beetles: implications for conservation. Journal of Zoology, 272, 235-243.

Rink, M. \& Sinsch, U. (2011) Warm summers negatively affect duration of activity period and condition of adult stag beetles (Lucanus cervus). Insect Conservation and Diversity, 4, 15-22.

Rudolf, V.H.W. \& Rödel, M.O. (2005) Oviposition site selection in a complex and variable environment: the role of habitat quality and conspecific cues. Oecologia, 142, 316-325. 
Schick, R.S., Loarie, S.R., Colchero, F., Best, B.D., Boustany, A., Conde, D.A., Halpin, P.N., Joppa, L.N., McClellan, C.M. \& Clark, J.S. (2008) Understanding movement data and movement processes: current and emerging directions. Ecology Letters, 11, 1338-1350.

Speight, M.C.D. (1989) Saproxylic Invertebrates and their Conservation. Council of Europe, Strasbourg, France.

Sprecher, E. (2003) The status of Lucanus cervus in Switzerland. Proceedings of the Second Pan-European Conference on Saproxylic Beetles (ed. by C.P. Bowen), pp. 6-8. People's Trust for Endangered Species, London, UK.

Sprecher-Uebersax, E. \& Durrer, H. (2001) Verhaltensstudien beim Hirschkäfer mittels Telemetrie und Videoaufzeichnungen (Coleoptera, Lucanus cervus L.). Mitteilungen der Naturforschenden Gesellschaften Beider Basel, 5, 161-182.

Svensson, G.P., Sahlin, U., Brage, B. \& Larsson, M.C. (2011) Should I stay or should I go? Modelling dispersal distances in a threatened saproxylic beetle, Osmoderma eremita, based on pheromone capture and radio telemetry. Biodiversity and Conservation, 20, 2883-2902.

Systat Software Inc (2008) San Jose, California. < www.systatsof tware.com $>$ 23rd August 2008.

Thomaes, A. (2009) A protection strategy for the stag beetle (Lucanus cervus, (L., 1758), Lucanidae) based on habitat requirements and colonisation capacity. Saproxylic Beetles their role and diversity in European woodland and tree habitats. Proceedings of the 5th Symposium and Workshop on the Conservation of Saproxylic Beetles, 89, 149-160.

Turchin, P. (1998) Quantitative Analysis of Movement: Measuring and Modelling Population Redistribution in Plants and Animals. Sinauer Associates, Sunderland, MA.

White, G.C. \& Garrott, R.A. (1990) Analysis of Wildlife RadioTracking Data. Academic Press, London, UK.

Worton, B.J. (1989) Kernel methods for estimating the utilization distribution in home-range studies. Ecology, 70, 164-168.

Zauli, A., Chiari, S., Hedenström, E., Svensson, G.P. \& Carpaneto, G.M. (2014) Using odour traps for population monitoring and dispersal analysis of the threatened saproxylic beetles Osmoderma eremita and Elater ferrugineus in central Italy. Journal of Insect Conservation, 18, 801-803.

Accepted 14 August 2017

First published online 10 September 2017

Editor: Simon Leather

Associate editor: Mats Jonsell 